\title{
Neuropotent self-renewing neural stem (NS) cells derived from mouse induced pluripotent stem (iPS) cells
}

\author{
Marco Onorati ${ }^{a}$, Stefano Camnasio ${ }^{\text {a }}$, Maurizio Binetti ${ }^{a}$, Christian B. Jung ${ }^{\text {, }}$ \\ Alessandra Moretti ${ }^{\mathrm{b}}$, Elena Cattaneo ${ }^{\mathrm{a}, *}$ \\ a Università degli Studi di Milano, Department of Pharmacological Sciences and Centre for Stem Cell Research, Via Balzaretti 9-20133 Milano, Italy \\ ${ }^{\mathrm{b}}$ Klinikum rechts der Isar and Deutsches Herzzentrum, Technical University of Munich, I. Medical Department-Molecular Cardiology, Ismaninger Strasse 22-81675 Munich, Germany
}

\section{A R T I C L E I N F O}

Article history:

Received 26 August 2009

Revised 7 November 2009

Accepted 9 December 2009

Available online 21 December 2009

\section{Keywords:}

Neural stem cells

Induced pluripotent stem cells

Neuropotency

Neuronal differentiation

\begin{abstract}
A B S T R A C T
Neural stem (NS) cells are a homogenous population of stem cells that expands in monolayer under serumfree conditions while remaining highly neuropotent. Here, we generated NS cells from induced pluripotent stem (iPS) cells that were previously derived from mouse fibroblasts (NS-(f)iPS). We showed that NS-(f)iPS cells exhibit long-term expansion and express markers of neurogenic radial glia. Analyses of the regional markers expressed in NS-(f)iPS cells suggested a ventral-rhombencephalic identity. Upon exposure to differentiation protocols, NS-(f)iPS cells produce neurons, astrocytes, and oligodendrocytes with an efficiency similar to ES-derived NS cells. NS-(f)iPS cells represent a new tool for studying neural cell fate determination and terminal differentiation, providing an interesting resource for experimental transplantation. Comparative studies between NS cells derived from iPS cells, reprogrammed from different somatic sources, and from authentic ES cells are necessary to identify critical elements for multipotency acquisition.

(C) 2009 Elsevier Inc. All rights reserved.
\end{abstract}

\section{Introduction}

An expected complication in future stem cell-based neurotransplantation medicine is the threat of immunorejection. One approach that might avoid this outcome is the use of pluripotent cells, derived from the patient, that can differentiate into the cells needed for transplantation. However, adult humans generally have very few suitably neurogenic stem cells and little is known about their multipotency. In the last few years, research has shown that during somatic reprogramming, epigenetic markers may be erased and remodeled in specialized cells, including fibroblasts (Okita et al., 2007; Takahashi and Yamanaka, 2006). This reprogramming causes a reversion back to an embryonic cell stage, which is endowed with pluripotency. This research represents a scientific breakthrough that promises to revolutionize biomedical studies; it provides a phenomenal tool for approaching stem cell biology and a strategy for understanding the mechanisms that give rise to pluripotency (for a review, see Yamanaka, 2009).

Induced pluripotency was first achieved in mouse fibroblasts with the transgenic expression of Oct4, Sox2, c-Myc, and Klf4 (Okita et al., 2007; Takahashi and Yamanaka, 2006). Consequently, it was also demonstrated that induced pluripotent stem (iPS) cells can be generated from mouse bone marrow cells (Takahashi and Yamanaka, 2006), hepatocytes, gastric epithelial cells (Aoi et al., 2008), pancreatic

\footnotetext{
* Corresponding author. Fax: +39025025843.

E-mail address: elena.cattaneo@unimi.it (E. Cattaneo).
}

cells (Stadtfeld et al., 2008), lymphocytes (Hanna et al., 2008), and adult neural stem cells (Kim et al., 2008; Silva et al., 2008; Kim et al., 2009). Remarkably, iPS cells were also generated from human fetal, neonatal, and adult skin fibroblasts (Nakagawa et al., 2008; Park et al., 2008; Takahashi et al., 2007; Yu et al., 2007) and keratinocytes (Aasen et al., 2008).

The advent of iPS cell technology has opened the possibility of generating cell-based patient-specific models of human disease and eventually therapeutics that preclude immunorejection. iPS cells derived from fibroblasts are expected to be similar to authentic ES cells. In fact, current reprogramming technologies allow the generation of iPS cells with a gene expression profile similar to ES cells, although more thorough analyses indicates that iPS cells still retain a unique gene expression signature, that differentiate them from ES cells (Chin et al., 2009). With respect to differentiation potential, iPS cells have been shown to give rise to the major specialized cell types, but more quantitative comparisons of their efficiency have not been reported.

In 2005, neural stem (NS) cells were isolated as an ad infinitum self-renewing population of multipotent cells, with the properties of neurogenic radial glia (Conti et al., 2005; Glaser et al., 2007; Pollard et al., 2006). These NS cells undergo long-term symmetric cell division in adherent cultures (Conti et al., 2005). NS cells have been efficiently derived from mouse ES cells and from fetal and adult mouse central nervous system (CNS) (Conti et al., 2005; Pollard et al., 2006). More recently, the generation and initial characterization of human fetal NS cells was described: these were tripotent, clonogenic, and euploid after long-term expansion (Sun et al., 2008). A similar (although not 
identical) NS cell type, named lt-hESNSCs (for long-term hESCderived neural stem cells), was derived from hES cells (Koch et al., 2009); these cells were capable of unlimited, homogenous expansion in monolayer.

Two recent studies have investigated the neurogenic properties of NS cells. In particular, it has been demonstrated that both adult subventricular zone (SVZ)-derived and ES-derived mouse NS cells consistently and reproducibly differentiate into molecularly and electrophysiologically mature neurons (Goffredo et al., 2008; Spiliotopoulos et al., 2009).

In an attempt at producing somatic stem cells from iPS cells, one group used adult brain-derived NS cells as a target for reprogramming; the generated iPS cells were then converted back into a population of multipotent NS cells, which were characterized by the expression of Sox2, Pax6, Olig2, Nestin, and Blbp (Kim et al., 2009).

The derivation of NS cells from reprogrammed fibroblasts would represent a valuable step towards attaining NS cells from human subjects. In this study, we describe the generation of a permanent population of NS cells that expresses a full complement of neural antigenic and biological properties, from fibroblast-derived iPS cells. We compared the expression of specific genes in these NS fibroblastderived iPS (NS-(f)iPS) cells with respect to that of ES-derived NS cells. We demonstrate for the first time that mouse fibroblast-derived iPS cells can be converted into a neuropotent, self-renewing NS cell population with radial glia properties. This population was stable for over 67 passages in culture and, when exposed to the appropriate protocols, gave rise to neurons, oligodendrocytes, and astrocytes. Following application of the Spiliotopoulos et al. (2009) differentiation protocol, $60 \%$ were defined as mature neurons by their molecular and biochemical features. We also compared the NS-(f)iPS cells to two ES-derived NS cell lines. The expression profile of a set of transcription factors indicative of regional identity showed that NS-(f)iPS cells exhibited ventral-rhombencephalic characteristics.

\section{Results}

\section{Derivation of self-renewing NS cells from iPS cells}

The iPS\#202 (Moretti et al., 2009) cells were subjected to a multistep protocol (Conti et al., 2005) for converting ES cells into a monolayer of self-renewing NS cells (Fig. 1A). After initial expansion on inactivated mouse embryonic fibroblast (MEF) feeder cells, iPS\#202 cells were adapted for at least three passages on gelatin in order to expose them to neural induction stimuli (Ying et al., 2003). Supplementary Fig. 1 shows that iPS\#202 cells, propagated on MEFs or on gelatin, were able to generate derivatives from embryoid bodies that represented the three embryonic germ layers in an RT-PCR analysis. In addition, beating cardiomyocytes were readily observed in both culture conditions (Videos S1 and S2).

Upon plating and culturing iPS\#202 cells in serum-free media, rosette-like structures appeared. After 10-12 days of induction, cells were replated and were able to support neural progenitor proliferation (Fig. 1A). Neurally committed iPS\#202 cells initially associated to form floating clusters that, after 3-4 days, were disaggregated and replated in fresh medium. Subsequently, cells grew with a typical bipolar NS cell morphology (Fig. 1A). These cells, called NS-(f)iPS cells, were continuously and homogenously propagated, with no significant variations in morphology or growth rate (not shown) for over 67 passages.
To investigate the neuropotent state of the newly generated NS-(f) iPS cells, we examined the expression of genes involved in somatic reprogramming (Fig. 1B). We found that the transgenes $c-M y c$, Sox2, and Klf4 were silenced in NS-(f)iPS cells and in the original iPS\#202 cells. On the other hand, Oct4 transgene expression appeared to be reactivated in NS-(f)iPS cells (Fig. 1B). Other authors have recently reported that some transgenes may be reactivated as iPS cells are pushed toward somatic differentiation (for a review, see Yamanaka, 2009). However, our analyses of the OCT4 protein in the same samples indicated that the gene product was undetectable by immunofluorescence and Western blot assays (Figs. 1C and D). This was probably due to regulation of Oct4 mRNA translation and/or protein degradation (Xu et al., 2004; Xu et al., 2009;).

We also confirmed that the endogenous Oct4, Sox2, c-Myc, and Klf4 genes were expressed in the original iPS\#202 cells growing on MEFs or on gelatin (Fig. 1B). Expression levels were similar to those observed in the ES IFRYFP cells, which were derived from the same Isl1:Cre/R26R-YFP mouse line that was used to derive the iPS\#202 cells. However, the expression of the same endogenous Oct4 and Klf4 genes and that of the pluripotency marker Nanog was promptly silenced in our newly derived NS-(f)iPS cells. This demonstrated that iPS cells remained sensitive to the genetic switch that characterizes the change in potency of NS cells (Fig. 1B). We also found that NS-(f) iPS cells expressed markers typically observed in authentic NS cells, including Sox2, Pax6, Glast, and Blbp; moreover, these were expressed at levels comparable to the levels observed in the ES-derived NS 46C CAG line (Conti et al., 2005) (Fig. 1B). These findings confirmed that the neural induction protocol was able to convert pluripotent fibroblast-derived iPS cells into neuropotent NS cells.

\section{NS-(f)iPS cells have features of neurogenic radial glia}

NS-(f)iPS cells maintained in self-renewing conditions were analyzed in more detail to investigate their neural identity. Nearly all NS-(f) iPS cells were immunopositive for Nestin/SOX2, Vimentin/PAX6, BLBP, GLAST, and Olig2 (Fig. 2A), a set of markers considered diagnostic for NS cells with radial glia properties (Conti et al., 2005). This demonstrated that NS-(f)iPS cells consisted of a homogeneous population of neurogenic stem cells. In self-renewing conditions, only few cells (1-2 cells/field) express BIII-tubulin or GFAP (Supplementary Figs. 2A and B).

NS cells generally have elongated bipolar morphology, end feet, and oval nuclei; during cell cycle progression, they show a dynamic morphological interconversion (Conti et al., 2005). Time-lapse videomicroscopy showed that NS-(f)iPS cells also underwent interkinetic nuclear migration (Video S3), a well-characterized phenomenon of nuclear movement along the entire length of the cell processes. These cells showed the in vivo behavior of neuroepithelial progenitor cells and radial glia during neurodevelopment. Therefore, NS-(f)iPS cells express the general morphological and molecular trademarks of radial glia cells.

To evaluate whether the reprogrammed NS-(f)iPS cells acquired a specific regional identity, we investigated the expression of a subset of transcription factors that establish positional identity along the rostro-caudal and dorso-ventral axes of the CNS. We compared the NS-(f)iPS cell expression pattern with that of the original NS 46C CAG line (Conti et al., 2005) and that of NS IFRYFP cells, a new line of NS cells we derived from ES IFRYFP cells (Supplementary Fig. 3). The NS 46C CAG and NS IFRYFP cells showed similar expression levels of the transcription factor-coding genes Tlx and Pax7 (Fig. 2B). However,

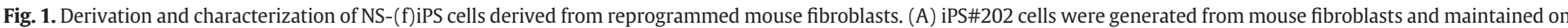

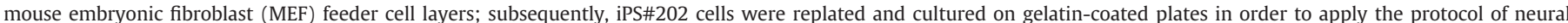

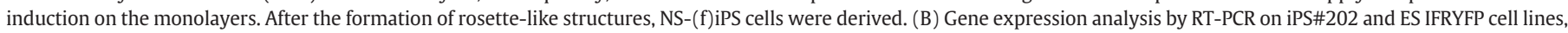

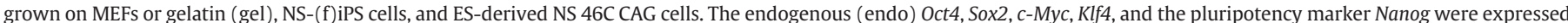

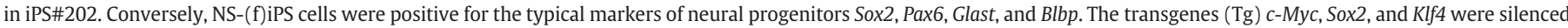

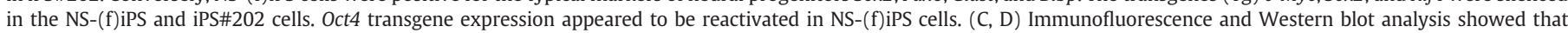
expression of OCT4 was undetectable in NS-(f)iPS cells. Positive control, iPS\#202 cells. 

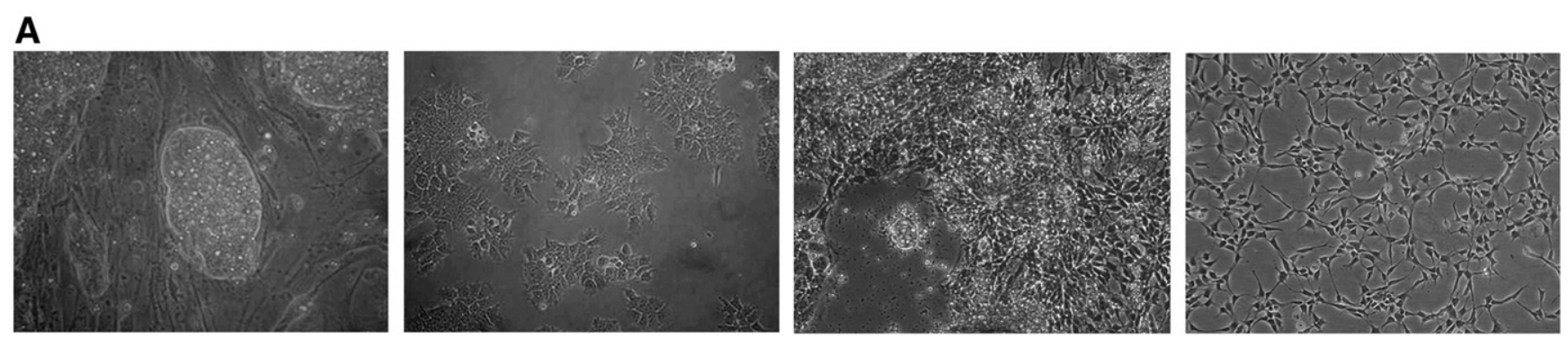

iPS\#202 cells
growing on MEFs $\rightarrow \begin{gathered}\text { iPS\#202 cells } \\ \text { in adherent culture }\end{gathered}$

adherent culture adaptation neural induction

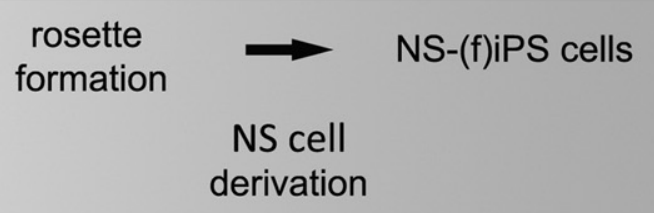

C

B

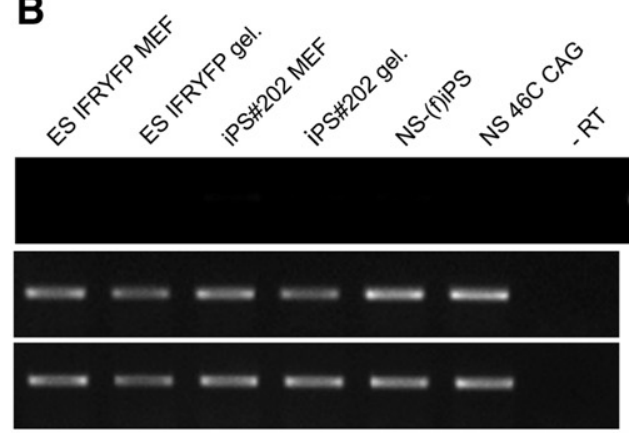

$\longrightarrow$

c-Myc $T g$

c-Myc endo

c-Myc total

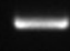

Sox2 $\mathrm{Tg}$

Sox2 endo

Sox2 total

$\longrightarrow$

KIf4 Tg

KIf4 endo

KIf4 total

Oct4 Tg

Oct4 endo

Oct4 total

Nanog

Pax6

Glast

Blbp

$\beta$-actin
D

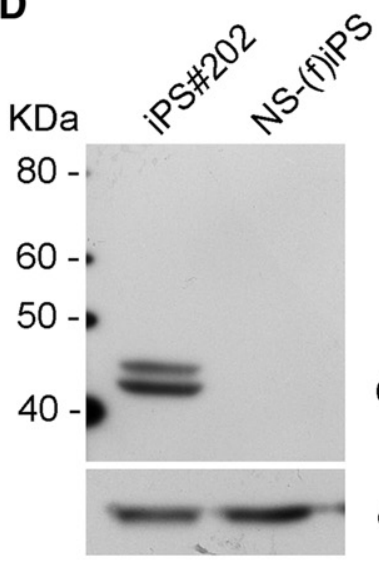

ОСТ3/4

$\alpha$-Tubulin
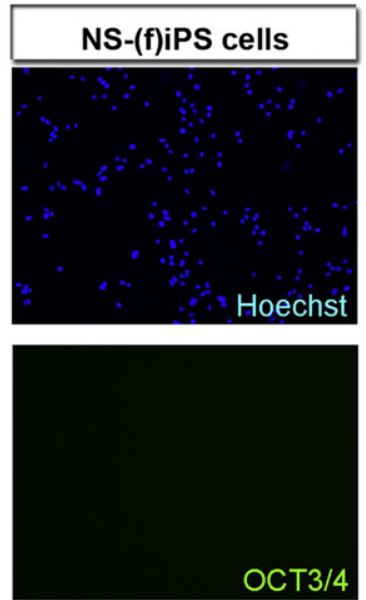
A
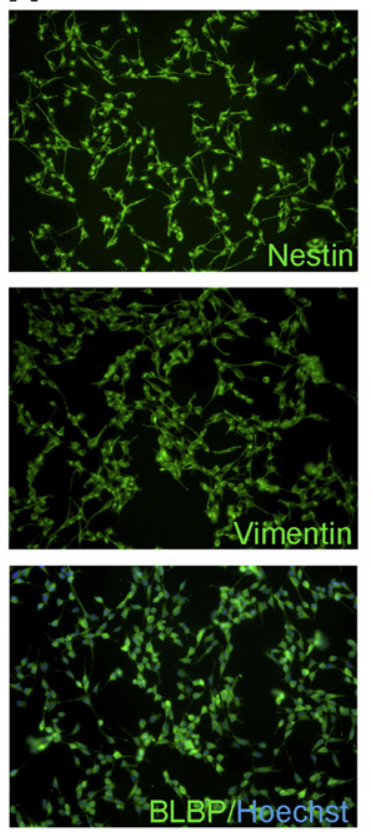
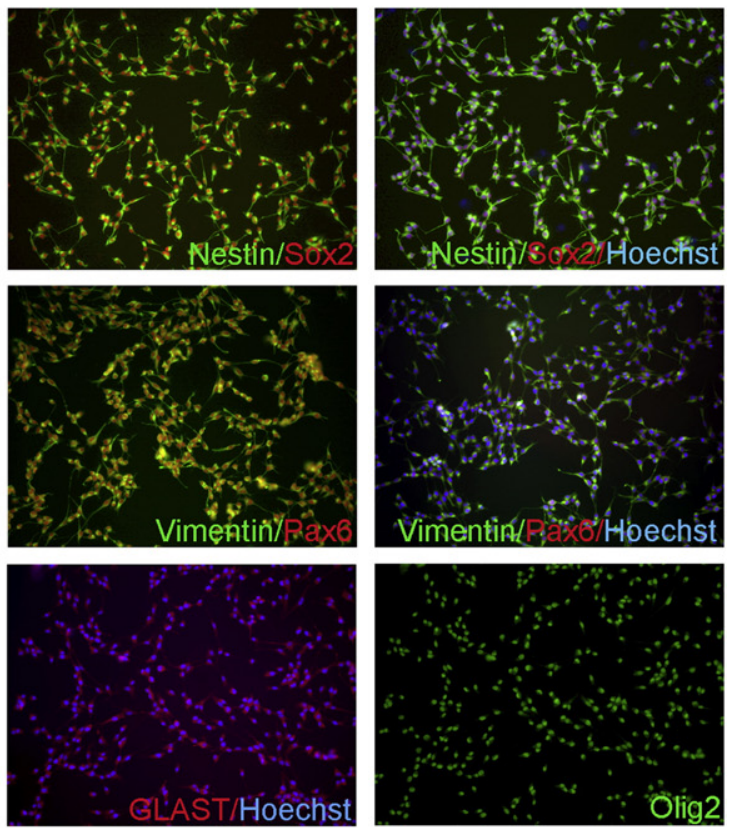

B
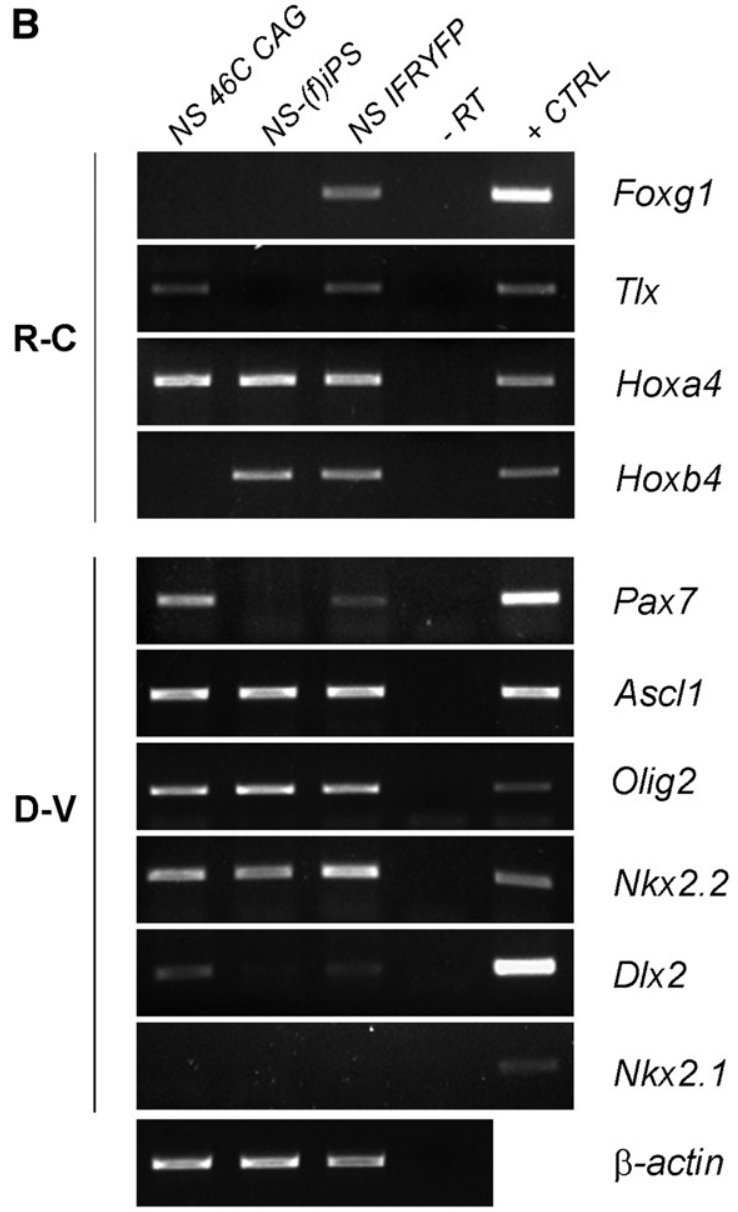

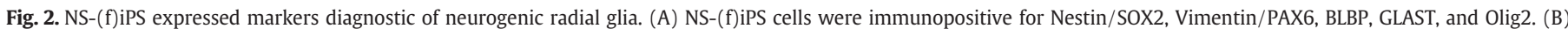

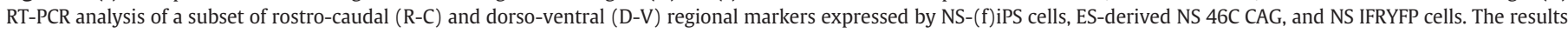
suggested a ventral-rhombencephalic regional identity for NS-(f)iPS cells.

NS-(f)iPS cells showed a distinct expression profile. In fact, NS-(f)iPS cells did not express the forebrain marker Tlx and the telencephalic marker Foxg1 but expressed the rhombencephalic/spinal gene
Hoxb4; thus, they exhibited a more caudal identity (Fig. 2B), which was confirmed by the expression of Hoxa4 (Fig. 2B). Moreover, NS-(f) iPS cells showed the expression of Nkx2.2, Ascl1, and Olig2 but do not 
express the dorsal marker Pax7, thus demonstrating a ventral identity. This set of markers indicated that NS-(f)iPS cells exhibited a ventralrhombencephalic identity. Furthermore, $D l \times 2$ was uniquely missing in the NS cells obtained from iPS\#202 cells (Fig. 2B).

These discrepancies between the NS cells derived from different sources may be due to either different exposure times to neural induction or different capabilities for responding to induction stimuli.

\section{NS-(f)iPS cells generate neurons, astrocytes, and oligodendrocytes}

NS cells are multipotent and give rise to neurons, oligodendrocytes, and astrocytes, the three primary lineages of the CNS (Conti et al.,
2005). To test neuronal commitment, we applied the Spiliotopoulos protocol recently optimized for ES-derived NS cells (Spiliotopoulos et al., 2009) based on the fact that these iPS cells are expected to behave similarly to ES cells. The protocol involved first EGF withdrawal, then a gradual decrease of FGF-2 and a simultaneous increase of BDNF in the differentiation medium up to a final concentration of $30 \mathrm{ng} / \mathrm{ml}$ (Fig. 3A). Considering that the original source of NS-(f)iPS cells were fibroblasts, results were remarkable in terms of morphological maturation of the cells and the acquisition of a neuronal phenotype. With differentiation, the neuronal precursors began to express the neuronal markers $\beta$ III-tubulin and MAP2 on day 5 (not shown), and expression increased in the following days. Initial experiments showed that after 22 days of differentiation, $27.7 \pm 2.2 \%$
A
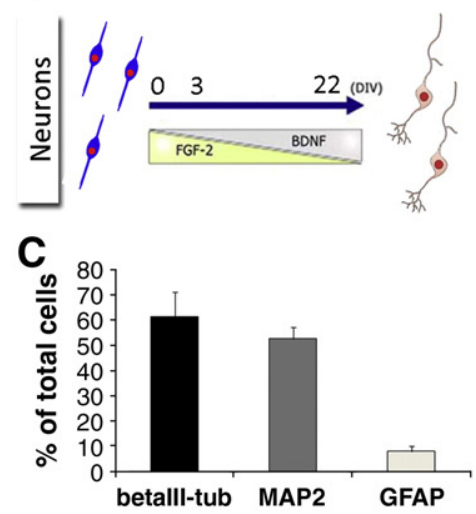

B
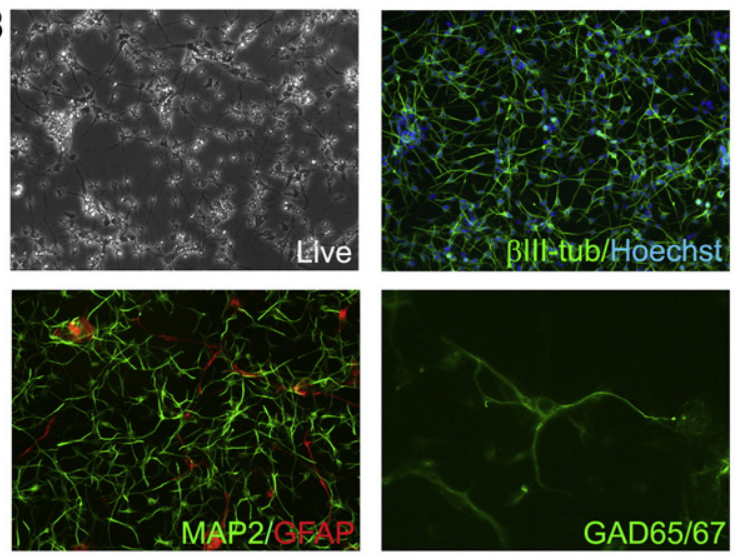

E

Meis2

Islet1

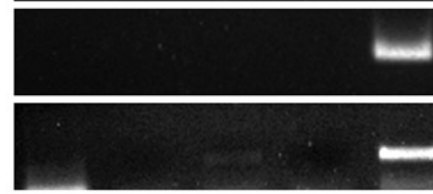

Islet1

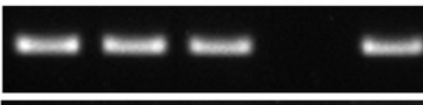

$H b 9$

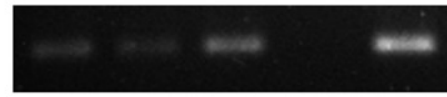

$N-C A M$

GAD1

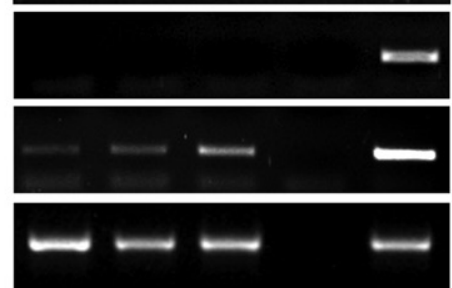

VGLUT2

Nav1.2

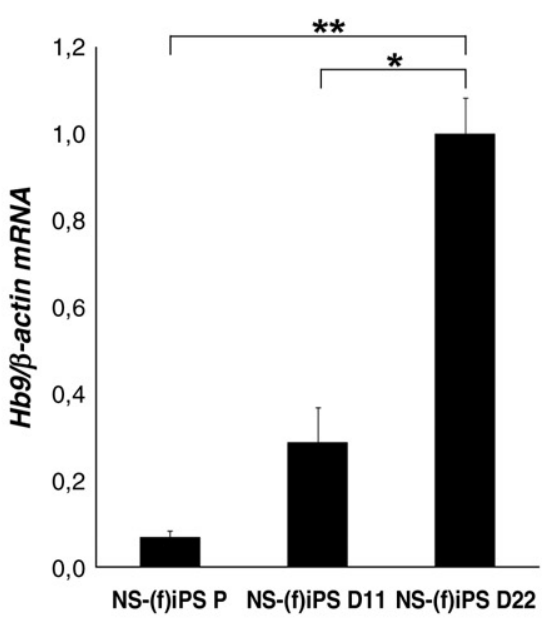

$\beta$-actin

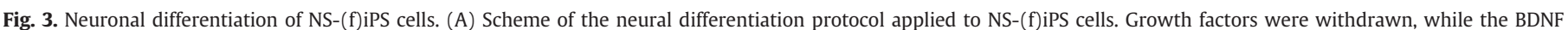

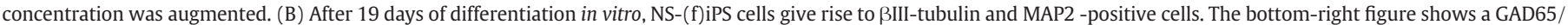

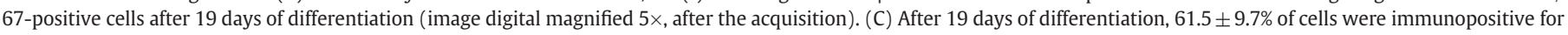

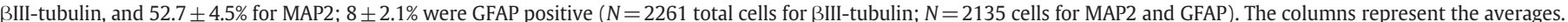

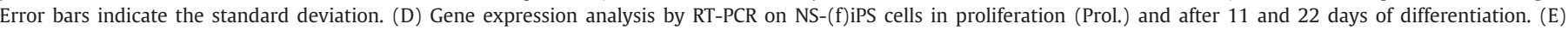

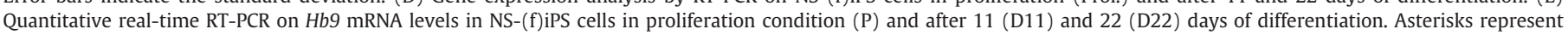
significant differences, as calculated by ANOVA analysis using the Tukey-Kramer post-test $\left({ }^{*} p<0.05\right.$, $\left.{ }^{* *} p<0.01\right)$. 
of the cells were immunopositive for $\beta$ III-tubulin and $28.9 \pm 1.9 \%$ for MAP2, while $14 \%$ of cells are GFAP positive (not shown). However, after setting the correct cell density $\left(5 \times 10^{5}\right.$ cells $\left./ \mathrm{cm}^{2}\right)$ and following addition of valproic acid, at the end of the differentiation protocol, cells exhibited thin elongated processes typical of mature neurons (Fig. 3B). The $61.5 \pm 9.7 \%$ of the cells were immunopositive for BIIItubulin and $52.7 \pm 4.5 \%$ for MAP2, while only a small fraction was GFAP positive $(8 \pm 2.1 \%$ ) (Figs. $3 \mathrm{~B}$ and $\mathrm{C}$ ). At the end of the differentiation, some Nestin-positive cells were still present, that however did not co-express BIII-tubulin (Supplementary Fig. 4). These results are comparable to that obtained for most ES-derived NS cell lines, considering that $80 \%$ of the differentiated cells expressed neuronal antigens (Spiliotopoulos et al., 2009).

We also performed RT-PCR to investigate the expression of a panel of neuronal markers at days 11 and 22 of differentiation (Fig. 3D). Meis2, a marker of intermediate-ventral neural tube cells, was expressed in proliferating and differentiating NS-(f)iPS cells (Fig. 3D). We did not detect the expression of Isl1, a marker of motoneurons, sensory neurons of the spinal cord, and striatal precursors (Fig. 3D). This result was consistent with the fact that the yellow fluorescent protein (YFP) reporter, which was under the control of the endogenous Isl1 gene, was not expressed in NS-(f)iPS cells (nor in NS cells derived from ES IFRYFP cells; data not shown). On the other hand, YFP fluorescence was observed in iPS\#202 cells that differentiated via embryoid bodies into neuronal cells (Supplementary Fig. 5). We also analyzed the expression of the marker neural cell adhesion molecule (N-CAM) and found that it was expressed in self-renewing and differentiating conditions (Fig. 3D).

Interestingly, the motoneuron marker $\mathrm{Hb} 9$ was expressed at the end of the differentiation period (Fig. 3D). Hb9 results significantly upregulated by quantitative real-time RT-PCR after 22 days of differentiation protocol with respect to proliferation condition $(p<0.01)$ and 11 days $(p<0.05)$ (Fig. 3E). The expression of this mRNA, which is specifically found in motor neurons, is consistent with the ventral-rhombencephalic identity shown by NS-(f)iPS cells.

By semiquantitative RT-PCR, we also showed a progressive increase in expression of the sodium voltage-gated channel, type II $\left(\mathrm{Na}_{\mathrm{v}} 1.2\right)$, a molecular marker that is typical of terminally differentiated neurons (Fig. 3D). With progressive differentiation, we also observed the upregulation of the gene encoding glutamic acid decarboxylase (GAD)-67 (Fig. 3D), and GAD65/67 immunopositive cells are shown in Fig. 3B. No expression of the vesicular glutamate transporter (VGLUT)-2 is present (Fig. 3D) as well as dopaminergic or serotonergic marks (not shown). Taken together, these data indicated that, with differentiation, these cells acquired general GABAergic features, as observed for ES-derived NS cells.
To test whether NS-(f)iPS cells could be induced to follow an oligodendroglial fate, the cells were plated on laminin-coated dishes and treated for 4 days with N2, forskolin, FGF-2, and PDGF, as described previously (Glaser et al., 2007). Terminal differentiation was obtained by culturing the cells in the presence of 3,3,5triiodothyronine (T3) and ascorbic acid (AA) for 4 days further (Glaser et al., 2007) (Fig. 4A). At the end of this differentiation treatment, nearly all cells present in the culture showed a branched oligodendrocyte-like morphology and were immunopositive for NG2 and 04, markers of an oligodendroglial precursor and for the mature oligodendrocyte, respectively. Approximately 25\% of the cells expressed both markers, demonstrating a commitment to the terminally differentiated fate (Fig. 4A).

To test the capacity of NS-(f)iPS cells to generate astrocytes, they were exposed to a medium without EGF and FGF-2, but with serum. After 5 days, the cells appeared flattened with large nuclei. All cells expressed the astrocytic marker GFAP (Fig. 4B).

Collectively, these results demonstrated that NS-(f)iPS cells have NS cell properties. They exhibit tripotency, as are capable of differentiating into the three primary cell types found in the CNS when exposed to the appropriate signals.

\section{Discussion}

NS cells are an indefinitely expandable source of neural progenitors that grow homogeneously in adherent cultures (Conti et al., 2005). They offer a promising system for dissecting the mechanisms of neural differentiation, are suitable for genetic and chemical highthroughput screening, and represent a potential source for cellreplacement therapies.

In this study, we demonstrated, for the first time, that reprogrammed mouse fibroblasts underwent a gradual, stepwise acquisition of neuropotency. In particular, we converted pluripotent iPS cells into neuropotent NS-(f)iPS cells that (1) expressed the appropriate markers for neural stem cells, (2) showed long-term stability up to 67 passages, (3) exhibited features of neurogenic radial glia and dynamic morphological changes during cell cycle progression, and (4) exhibited tripotent differentiation potential, by generating oligodendrocyte, astrocytes, and mature neurons. These findings established that self-renewing multipotent NS-(f)iPS cells can be derived from reprogrammed mouse fibroblasts.

Recent works also demonstrated that iPS cells can be differentiated into neurons by applying the developmental signals that are typically employed in ES cell differentiation protocols. For example, Wernig et al. (2008) demonstrated that mouse fibroblast-derived iPS cells could differentiate into dopamine neurons (Wernig et al., 2008). Upon
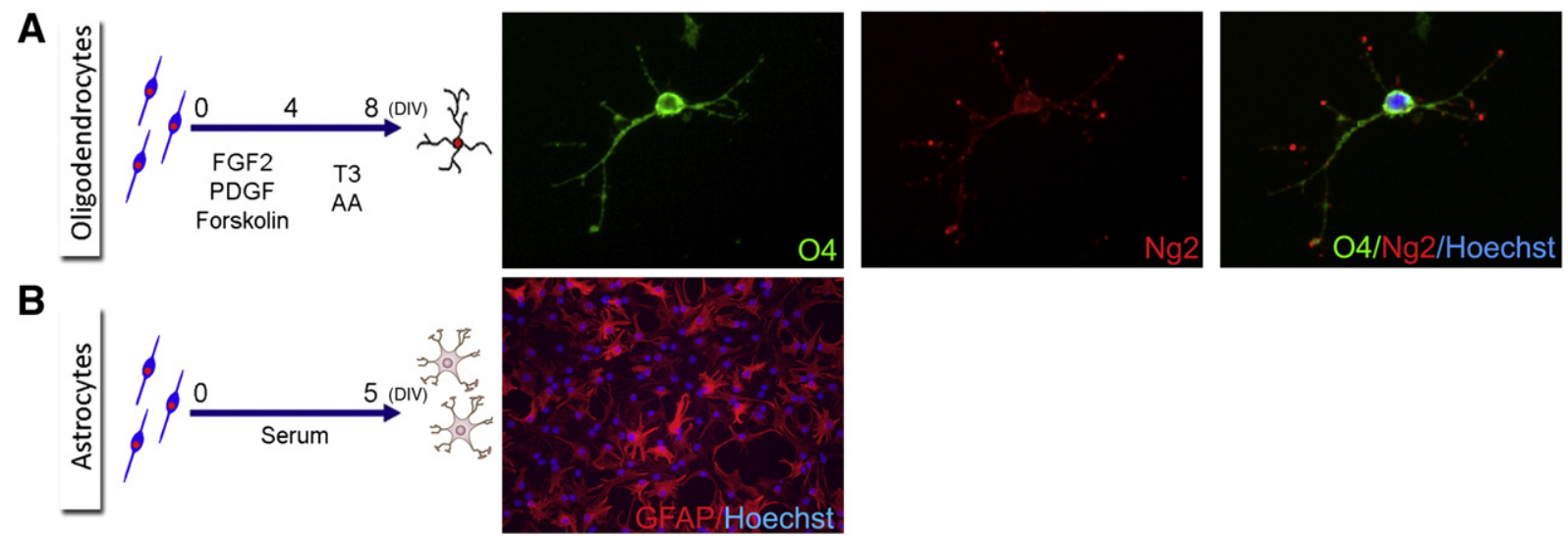

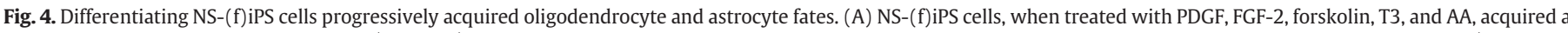

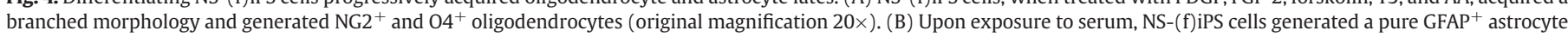
population with a flat, sheet-like morphology. 
transplantation into the adult brain, these neurons were able to ameliorate the behavioral deficits in the Parkinsonian rat model. Another recent study examined the potential of iPS cells as a source of transplant tissue for the auditory system. The authors demonstrated that iPS cell-derived neurons were able to innervate hair cells ex vivo, then after in vivo transplantation into the cochlea, they survived and acquired a glutamatergic phenotype (Nishimura et al., 2009). Furthermore, two studies described the characterization of iPS cells derived from patients with a neurodegenerative disease, thus validating iPS cells as a potential in vitro model of human diseases (Dimos et al., 2008; Ebert et al., 2009).

In this study, we also generated a line of NS cells from the ES IFRYFP cell line that was derived from the same mouse strain that was used to derive iPS\#202 cells. In our hands, both the ES- and iPSderived NS cells exhibited similar expression of neural stem cell markers. The ES-derived NS cells expressed a pattern of transcription factors that delineated their regional identity within specific CNS domains. Interestingly, NS-(f)iPS cells expressed a peculiar set of genes, like Hoxa4, Hoxb4, Nkx2.2, Olig2, and Ascl1, that could delineate a ventro-caudal identity, confirmed by the lack of the expression of the anterior marker Tlx, Foxg1, and the dorsal one Pax7. In addition, NS-(f)iPS cells appeared to have an efficiency similar to ES-derived NS cells in generating neurons upon exposure to differentiating media. Of note, the differentiating protocol was optimized for NS cells derived from authentic ES cells, although it was based on the Spiliotopoulos protocol (Spiliotopoulos et al., 2009).

Finally, we also evaluated the NS derivation protocol for the ability to give rise to progenitors of medium spiny striatal neurons that expressed the Islet1 gene. However, although the Islet1 promoter was perfectly functional in the original ES IFRYFP cells and in iPS\#202 cells (see Supplementary Fig. 5), the NS derivation protocol rendered these cells incapable of entering an Islet $1^{+}$cell fate. Screening for new genetic determinants of the striatal cell lineage is ongoing in NS cells (unpublished).

This work demonstrated that reprogrammed fibroblasts could be efficiently converted into a homogeneous population of NS cells. Our results suggest that NS-(f)iPS cells could represent a novel source for supporting iPS cell technology and in vitro modeling of neurological diseases in regenerative medicine.

\section{Experimental methods}

\section{Cell culture and neural induction}

iPS\#202 cells were generated from fibroblasts of Isl1:Cre/R26R-YFP mice, according to the protocol described by Yamanaka (2009). ES IFRYFP9 cells were derived from the same Isl1:Cre/R26R-YFP mouse line that was used to derive the iPS\#202 cells. iPS\#202 and ES IFRYFP9 cells were maintained on mitomycin-treated MEF feeder cell layers, cultured in Dulbecco's Modified Eagle's Medium (DMEM; GIBCO, Invitrogen), supplemented with $15 \%$ fetal bovine serum (FBS; GIBCO, Invitrogen), $2 \mathrm{mM}$ L-glutamine, $0.1 \mathrm{mM}$ nonessential amino acids, $1 \mathrm{mM}$ sodium pyruvate, $0.1 \mathrm{mM} \beta$-mercaptoethanol, $5 \mathrm{mg} / \mathrm{ml}$ penicillin, $100 \mathrm{mg} / \mathrm{ml}$ streptomycin, and $10^{3} \mathrm{U} / \mathrm{ml}$ leukemia inhibitory factor (LIF, Chemicon International). Subsequently, iPS\#202 cells were replated and cultured without MEFs on $0.1 \%$ gelatin-coated $100-\mathrm{mm}$ tissue culture dish (IWAKI, Bibby Scientific) for at least three passages in Glasgow Minimum Essential Medium (GMEM; GIBCO, Invitrogen) supplemented with 10\% FBS, $2 \mathrm{mM}$ L-glutamine, $0.1 \mathrm{mM}$ nonessential amino acids, $1 \mathrm{mM}$ sodium pyruvate, $0.1 \mathrm{mM} \beta$-mercaptoethanol, $5 \mathrm{mg} / \mathrm{ml}$ penicillin, $100 \mathrm{mg} /$ $\mathrm{ml}$ streptomycin, and $10^{3} \mathrm{U} / \mathrm{ml}$ LIF.

For monoculture differentiation, undifferentiated iPS\#202 cells were dissociated and plated onto gelatin-coated 6-well tissue culture plate (IWAKI) at a density of $8 \times 10^{4}$ cells/well and cultured in N2B27 medium that contained a 1:1 mixture of DMEM/F12 supplemented with 1\% N2 (Invitrogen) and Neurobasal medium supplemented with 2\% B27 (Invitrogen). Medium was renewed every day. Cells were maintained for 12 days and then were plated on uncoated T-25 flask (IWAKI) in Euromed-N medium (Euroclone, Milan, Italy), supplemented with $\mathrm{N} 2$ and $20 \mathrm{ng} / \mathrm{ml}$ of both EGF and FGF-2 (NS expansion medium). Over 3-5 days, cells formed aggregates that subsequently attached to the plastic upon disaggregation. After 2-3 passages, monolayers of NS cells were generated, and these were referred to as NS-(f)iPS cells.

\section{Embryoid bodies assay}

Embryoid bodies (EBs) were generated with the "hanging drops" method, where 1000 cells/drop were plated on the lid of a bacterial dish (Sterilin) in GMEM medium supplemented with 10\% FBS, 2 mM L-glutamine, $0.1 \mathrm{mM}$ nonessential amino acids, $1 \mathrm{mM}$ sodium pyruvate, $0.1 \mathrm{mM} \beta$-mercaptoethanol, $5 \mathrm{mg} / \mathrm{ml}$ penicillin, $100 \mathrm{mg} / \mathrm{ml}$ streptomycin, and no LIF. On day 2, EBs were transferred to a nonadherent bacterial dish and were grown in suspension for another 3 days. At day 5 of differentiation, the EBs were transferred to $0.1 \%$ gelatin-coated tissue culture dishes (IWAKI), and the medium was changed every 3-4 days. Starting on day 6 of differentiation, each EB outgrowth was examined daily for spontaneously beating regions.

\section{Cell culture of NS cells}

NS cells were routinely cultured in NS proliferation medium, composed of Euromed-N medium with N2 supplement, $20 \mathrm{ng} / \mathrm{ml} \mathrm{EGF}$ (Peprotech Inc.), and $20 \mathrm{ng} / \mathrm{ml}$ FGF-2 (Peprotech Inc.). All NS-(f)iPS cells were studied between passages 5 and 67. For routine passaging, NS-(f)iPS cells were dissociated with Accutase (Sigma) and split 1:4 or $1: 5$ every $2-3$ days.

\section{Differentiation of NS-(f)iPS cells}

NS-(f)iPS cells were differentiated according to an optimized protocol in serum-free conditions (Spiliotopoulos et al., 2009). Briefly, proliferating cells were collected following Accutase treatment and then plated on T-25 flask (IWAKI) in Euromed-N medium supplemented with $5 \mathrm{mg} / \mathrm{ml}$ penicillin/streptomycin (Gibco, Invitrogen), $5 \mathrm{mg} / \mathrm{ml} \mathrm{L-glutamine} \mathrm{(Gibco,} \mathrm{Invitrogen),} \mathrm{1 \%} \mathrm{B27} \mathrm{(Gibco,}$ Invitrogen), 0.5\% N2 (Gibco, Invitrogen), and $10 \mathrm{ng} / \mathrm{ml} \mathrm{FGF-2}$ (Peprotech, Tebu-Bio). After 3 days the cultures were dissociated with Accutase and the cells were then plated onto laminin-coated dishes in 1/4 DMEM F12 (Invitrogen) medium plus 3/4 Neurobasal (Invitrogen) medium supplemented with $5 \mathrm{mg} / \mathrm{ml}$ penicillin/ streptomycin, $5 \mathrm{mg} / \mathrm{ml}$ L-glutamine, $1 \%$ B27, 0.5\% N2, $10 \mathrm{ng} / \mathrm{ml}$ FGF-2, $20 \mathrm{ng} / \mathrm{ml}$ BDNF (Peprotech, Tebu-Bio), and $1 \mathrm{mM}$ valproic acid (Sigma) and cultured for an additional 3 days. Subsequently, for terminal differentiation, the cultures were exposed to 1/4 DMEM F12 medium plus 3/4 Neurobasal medium supplemented with $5 \mathrm{mg} / \mathrm{ml}$ penicillin/streptomycin, $5 \mathrm{mg} / \mathrm{ml}$ L-glutamine, $1 \% \mathrm{~B} 27,0.5 \% \mathrm{~N} 2$, $6.6 \mathrm{ng} / \mathrm{ml} \mathrm{FGF-2,} 30 \mathrm{ng} / \mathrm{ml} \mathrm{BDNF}$, and $1 \mathrm{mM}$ valproic acid for other 3 days. Then, the cells were maintained in the same medium, but with $5 \mathrm{ng} / \mathrm{ml} \mathrm{FGF-2.}$

For differentiation into the astrocytic lineage, NS-(f)iPS cells were exposed to $10 \%$ serum in GMEM medium and cultured for 5 days.

For oligodendroglial differentiation (Glaser et al., 2007), NS-(f)iPS cells were plated on laminin-coated dishes in DMEM/F12 medium supplemented with N2, FGF-2 $10 \mathrm{ng} / \mathrm{ml}$, PDGF (10 ng/ml; R\&D Systems), and forskolin (10 mM; Sigma, Steinheim, Germany) for 4 days to support a glial precursor stage. Then, differentiation was induced by a 4-day growth factor withdrawal in the presence of 3,3,5-triiodothyronine (T3; $30 \mathrm{ng} / \mathrm{ml}$; Sigma) and ascorbic acid (AA; $200 \mathrm{mM}$; Sigma). 


\section{Immunofluorescence}

Cell cultures were fixed with $4 \%$ paraformaldehyde for 15 min at room temperature. For labeling intracellular antigens, cells were permeabilized in PBS containing 0.5\% Triton X-100. After washing in PBS, cells were blocked with 5\% fetal calf serum in PBS for $1 \mathrm{~h}$ and incubated overnight in 3\% fetal calf serum in PBS with the following primary antibodies: Nestin (1:200, Becton Dickinson), Vimentin (1:100, Developmental Studies Hybridoma Bank), Pax6 (1:100, MBL Eppendorf), Sox2 (1:100, Chemicon), BLBP (1:1000, Chemicon), GLAST (1:1000, Chemicon), Olig2 (1:500, Chemicon), GFAP (1:800, Dako), MAP2 (1:500, Becton Dickinson), $\beta$-III tubulin (1:1000, Promega), 04 (1:50, Chemicon), NG2 (1:300, Chemicon), Oct4 (1:100, Santa Cruz), GAD65/67 (1:200, DSHB), and Nanog (1:500, Novos Biological). After two washes in PBS, appropriate secondary antibodies conjugated to Alexa fluorophores 488 or 568 (Molecular Probes, Invitrogen) were diluted at 1:500 in blocking solution and mixed with Hoechst 33258 ( $5 \mu \mathrm{g} / \mathrm{ml}$; Molecular Probes, Invitrogen) to counterstain the nuclei. The solution was applied for $1 \mathrm{~h}$ at room temperature. The cells were then washed twice in PBS buffer. Images were acquired with a Leica DMI $6000 \mathrm{~B}$ microscope $(20 \times$ objective) with LAS-AF imaging software and then processed with Adobe Photoshop.

\section{RT-PCR analysis}

Total RNA was extracted from NS-(f)iPS cells with Trizol reagent (Invitrogen) according to the manufacturer's procedures. Before reverse-transcription, RNA was treated with DNaseI (Qiagen) and purified with the RNeasy kit (Qiagen). The cDNA was generated with Superscript III Reverse Transcriptase (Invitrogen) according to the manufacturer's procedures. One microgram of total RNA was used to produce cDNA. RT-PCR was performed for 30 cycles for all markers, except $\mathrm{Hb9}$ ( 35 cycles), as follows: denaturing for $45 \mathrm{~s}$ at $94{ }^{\circ} \mathrm{C}$; annealing for $30 \mathrm{~s}$, extension at $72{ }^{\circ} \mathrm{C}$. PCR products were resolved on a $2 \%$ agarose gel. Primer sequences, annealing temperature, and product sizes are listed in Table 1.

\section{Quantitative real-time RT-PCR analysis}

RT-qPCR analyses were done in triplicate for the analyzed gene. iCycler Thermal Cycler with Multicolor Real-Time PCR Detection System (Bio-Rad) was used. All reactions were performed in a total volume of $25 \mu$ l containing $50 \mathrm{ng}$ of cDNA, $50 \mathrm{mM} \mathrm{KCl,} 20 \mathrm{mM}$ Tris- $\mathrm{HCl}$, pH 8.4, $0.2 \mathrm{mM}$ dNTPs, $25 \mathrm{U} / \mathrm{ml}$ iTaq DNA polymerase, $3 \mathrm{mM} \mathrm{MgCl}$, SYBR Green I, 10 nM fluorescein, stabilizers (iQ SYBR Green Supermix; BioRad), and $0.2 \mu \mathrm{M}$ of forward and reverse primers. Amplification cycles consisted of an initial denaturing cycle at $95^{\circ} \mathrm{C}$ for $3 \mathrm{~min}$, followed by 45 cycles of $30 \mathrm{~s}$ at $95^{\circ} \mathrm{C}, 30 \mathrm{~s}$ at $60^{\circ} \mathrm{C}$, and $30 \mathrm{~s}$ at $72{ }^{\circ} \mathrm{C}$. Fluorescence was quantified during the $60{ }^{\circ} \mathrm{C}$ annealing step, and product formation was confirmed by a melting curve analysis $\left(55-94{ }^{\circ} \mathrm{C}\right)$. Amounts of target gene mRNA were normalized to a reference gene $\beta$-actin. Primer sequences, annealing temperature, and product sizes are listed in Table 1. Statistical analysis was performed by means of oneway ANOVA and Tukey-Kramer multiple comparison test.

Table 1

RT-PCR primer sequences, related conditions, and amplicons.

\begin{tabular}{|c|c|c|c|c|}
\hline Gene & Forward primer & Reverse primer & $\mathrm{Ta}$ & Product size (bp) \\
\hline Ascl1 & CGTCCTCTCCGGAACTGAT & CGTCCTCTCCGGAACTGAT & 56 & 482 \\
\hline$\beta$-Actin & GGCCCAGAGCAAGAGAGGTATCC & ACGCACGATTTCCCTCTCAGC & 58 & 460 \\
\hline$\beta$-Actin (RT-qPCR) & AGTGTGACGTTGACATCCGTA & GCCAGAGCAGTAATCTCCTTCT & 60 & 112 \\
\hline Blbp & GGGTAAGACCCGAGTTCCTC & ATCACCACTTTGCСАССТTC & 56 & 213 \\
\hline Bmp4 & TGTGAGGAGTTTCCATCACG & TGTGAGGAGTTTCCATCACG & 55 & 547 \\
\hline Brachyury (T) & GTGACTGCCTACCAGAATGA & ATTGTCCGCATAGGTTGGAG & 56 & 336 \\
\hline c-Myc endo & TGACCTAACTCGAGGAGGAGCTGGAATC & AAGTTTGAGGCAGTTAAAATTATGGCTGAAGC & 60 & 170 \\
\hline c-Myc total & CAGAGGAGGAACGAGCTGAAGCGC & TTATGCACCAGAGTTTCGAAGCTGTTCG & 60 & 228 \\
\hline c-Myc Tg & CTGGAATCTCTCGTGAGAGTAA & CACTTTGTACAAGAAAGCTGGG & 57 & 250 \\
\hline Dlx2 & AACCACGCACCATCTACTCC & CCGCTTTTCCACATCTTCTT & 54 & 181 \\
\hline Foxg1 & CTGAGTGTGGACCGGCTG & CGTGCTGGTCTGCGAAGTC & 58 & 213 \\
\hline Gad1 & TGGCATCTTCCACTCCTTCG & GCTACGCCACACCAAGTATC & 56 & 132 \\
\hline Gata4 & AGCAGCAGCAGCAGCAGTGA & ATGTCTGAGTGACAGGAGATGC & 59 & 190 \\
\hline Glast & CCAAAAGCAACGGAGAAGAG & ACCTCCCGGTAGCTCATTTT & 56 & 229 \\
\hline$H b 9$ & TCGAACCTCTTGGGGAAGTG & AATCTTCACCTGAGTCTCGGT & 61 & 159 \\
\hline Hoxa4 & TGTGCССТАСТСАТСTCCTG & GCTGTCTGGCTGACTCAAAG & 53 & 260 \\
\hline Hoxb4 & TGCAAAGAGCCCGTCGTC & GGAACCAGATCTTGATCTGGCG & 60 & 185 \\
\hline Islet-1 & CGTCTGATTTCCCTGTGTGTTGG & AAGTCGTTCTTGCTGAAGCCTATG & 58 & 239 \\
\hline Klf4 endo & GCGAACTCACACAGGCGAGAAACC & TCGCTTCCTCTTCCTCCGACACA & 60 & 711 \\
\hline Klf4 total & CGTGGCTGCCAGAAACACAG & CTGTTCTTTTCCGGGGCCACG & 60 & 730 \\
\hline Klf4 Tg & AAGCCATTATTGTGTCGGAGGA & CACTTTGTACAAGAAAGCTGGG & 57 & 500 \\
\hline Meis2 & GAGACGTCTGTTCCTCTGACTC & TCTCATCAATCACGAGGTCAATGG & 58 & 243 \\
\hline Nanog & ATGAAGTGCAAGCGGTGGCAGAAA & CCTGGTGGAGTCACAGAGTAGTTC & 56 & 464 \\
\hline Nav1.2 & GATACCTCGCCCTGCTAACAA & AGGATCATGATGCTGATGTCAAAC & 60 & 84 \\
\hline$N-C A M$ & CAGTCTGAGGCCACTGTCAA & GACATCTCGGCCTTTGTGTT & 58 & 162 \\
\hline$N k \times 2.1$ & ACCGGGTTCAGACTCAGTTC & ATCGACATGATTCGGCGTCGG & 60 & 221 \\
\hline$N k \times 2.2$ & AAAGGTATGGAGGTGACGCCT & AGCTGTACTGGGCGTTGTACT & 60 & 190 \\
\hline Oct4 endo & TCTTTCCACCAGGCCCCCGGCTC & TGCGGGCGGACATGGGGAGATCC & 60 & 224 \\
\hline Oct4 total & CTGAGGGCCAGGCAGGAGCACGAG & CTGTAGGGAGGGCTTCGGGCACTT & 60 & 485 \\
\hline Oct4 $\mathrm{Tg}$ & GCTACAGGGACACCTTTCCCA & CACTTTGTACAAGAAAGCTGGG & 57 & 200 \\
\hline Olig2 & GGCGGTGGCTTCAAGTCATC & TAGTTTCGCGCCAGCAGCAG & 60 & 260 \\
\hline Otx2 & TACCTCAGTCCCAACCATTG & TCTGAGAGCATCGTTCCATC & 58 & 572 \\
\hline Pax6 & AGTCACAGCGGAGTGAATCAGC & AGCCAGGTTGCGAAGAACTCTG & 58 & 426 \\
\hline Pax7 & GTCACTAAGCATGGGTAGATG & GCTACCAGTACAGCCAGTATG & 56 & 328 \\
\hline Sox2 endo & TAGAGCTAGACTCCGGGCGATGA & TTGCCTTAAACAAGACCACGAAA & 56 & 297 \\
\hline Sox2 total & GGTTACСTCTTCCTCССАСТCCAG & TCACATGTGCGACAGGGGCAG & 60 & 193 \\
\hline Sox2 $\mathrm{Tg}$ & ATTTGGAATCAGGCTGCCGAGA & CACTTTGTACAAGAAAGCTGGG & 56 & 230 \\
\hline Synapsin I & GGTGGATTCTCTGTGGACATGGAA & AGTTCTGCCCAATCTTCTGGACACG & 62 & 493 \\
\hline Tlx & TGTGGTGACCGCAGCTC & TCGACACGCCCTGCATTG & 58 & 168 \\
\hline Vglut2 & TCGGCTTCTGCATATCCTTC & CCTGGAATCTGGGTGATGAT & 56 & 190 \\
\hline
\end{tabular}

Ta: annealing temperature, ${ }^{\circ} \mathrm{C}$. 


\section{Western blot}

Cells were washed with ice-cold PBS and lysed with $100 \mu \mathrm{l}$ of icecold lysis buffer containing $1 \%(\mathrm{v} / \mathrm{v}$ ) Triton X-100, $50 \mathrm{mM}$ Tris- $\mathrm{HCl}$, $\mathrm{pH}$ 7.2, $1 \mathrm{mM}$ phenylmethylsulfonyl fluoride, $100 \mathrm{mM} \mathrm{NaCl}, 5 \mathrm{mM}$ EGTA, protease inhibitor cocktail (Sigma), and phosphatase inhibitor cocktail 1 (Sigma). After $30 \mathrm{~min}$ of incubation at $4{ }^{\circ} \mathrm{C}$ on a shaker, lysates were cleared by centrifugation for $20 \mathrm{~min}$ at $12,000 \times \mathrm{g}$ and $4{ }^{\circ} \mathrm{C}$. After protein quantification with a BCA assay (Pierce), protein samples were loaded onto an $8 \%$ polyacrylamide gel for size separation. Subsequently, proteins were transferred to a PVDF Hybond-P membrane (GE Healthcare) by electroblotting for $3 \mathrm{~h}$. Blots were blocked for $1 \mathrm{~h}$ in $5 \%$ nonfat dry milk with TBS-T $(10 \mathrm{mM}$ Tris-HCl, pH 8.0, 150 mM NaCl, 0.05\% v/v Tween-20; Sigma). After overnight incubation at $4{ }^{\circ} \mathrm{C}$ with monoclonal primary anti-OCT4 (Santa Cruz, dilution 1:500) and anti $\alpha$-tubulin antibodies (Sigma, dilution 1:2000), filters were incubated for $1 \mathrm{~h}$ at room temperature with secondary anti-mouse $\operatorname{IgG}$ antibody (peroxidase conjugate, Biorad, 1:3000) and then washed three times with TBS-T to remove excess antibody. The SuperSignal West Pico Chemiluminescent Substrate (Pierce) was used to visualize immunoreactive bands by exposure to Amersham Hyperfilm ECL (GE Healthcare).

\section{Acknowledgments}

The initiation of this work was supported by a grant from Fondazione Cariplo (Italy) in the context of the awarded N.O.B.E.L. (Operational Network for Biomedicine par Excellence in Lombardy) project entitled "A genetic toolkit for the analyses of neural stem cellsacronym: Mouse NS-toolkit". This work is also supported by EuroSystem (FP7, European Union Health-F4-2008-200720) and NeuroStemcell (FP7, European Union HEALTH-2008-B-222943). The laboratory acknowledges the valuable contributions of Unicredit Banca S.p.A. (Italy) and of Tavola Valdese (Italy). We also thank the families of patients with Huntington's disease for their continuous support.

\section{Appendix A. Supplementary data}

Supplementary data associated with this article can be found, in the online version, at doi:10.1016/j.mcn.2009.12.002.

\section{References}

Aasen, T., Raya, A., Barrero, M.J., Garreta, E., Consiglio, A., Gonzalez, F., Vassena, R., Bilic J., Pekarik, V., Tiscornia, G., Edel, M., Boue, S., Belmonte, J.C., 2008. Efficient and rapid generation of induced pluripotent stem cells from human keratinocytes. Nat. Biotechnol. 26, 1276-1284.

Aoi, T., Yae, K., Nakagawa, M., Ichisaka, T., Okita, K., Takahashi, K., Chiba, T., Yamanaka, S., 2008. Generation of pluripotent stem cells from adult mouse liver and stomach cells. Science 321, 699-702.

Chin, M.H., Mason, M.J., Xie, W., Volinia, S., Singer, M., Peterson, C., Ambartsumyan, G., Aimiuwu, O., Richter, L., Zhang, J., Khvorostov, I., Ott, V., Grunstein, M., Lavon, N. Benvenisty, N., Croce, C.M., Clark, A.T., Baxter, T., Pyle, A.D., Teitell, M.A., Pelegrini, M., Plath, K., Lowry, W.E., 2009. Induced pluripotent stem cells and embryonic stem cells are distinguished by gene expression signatures. Cell Stem Cell 5, 111-123.

Conti, L., Pollard, S.M., Gorba, T., Reitano, E., Toselli, M., Biella, G., Sun, Y., Sanzone, S. Ying, Q.L., Cattaneo, E., Smith, A., 2005. Niche-independent symmetrical selfrenewal of a mammalian tissue stem cell. PLoS Biol. 3, e283.

Dimos, J.T., Rodolfa, K.T., Niakan, K.K., Weisenthal, L.M., Mitsumoto, H., Chung, W., Croft, G.F., Saphier, G., Leibel, R., Goland, R., Wichterle, H., Henderson, C.E., Eggan, K., 2008. Induced pluripotent stem cells generated from patients with ALS can be differentiated into motor neurons. Science 321, 1218-1221.
Ebert, A.D., Yu, J., Rose Jr., F.F., Mattis, V.B., Lorson, C.L., Thomson, J.A., Svendsen, C.N., 2009. Induced pluripotent stem cells from a spinal muscular atrophy patient. Nature 457, 277-280.

Glaser, T., Pollard, S.M., Smith, A., Brustle, O., 2007. Tripotential differentiation of adherently expandable neural stem (NS) cells. PLoS One 2, e298.

Goffredo, D., Conti, L., Di Febo, F., Biella, G., Tosoni, A., Vago, G., Biunno, I., Moiana, A., Bolognini, D., Toselli, M., Cattaneo, E., 2008. Setting the conditions for efficient, robust and reproducible generation of functionally active neurons from adult subventricular zone-derived neural stem cells. Cell Death Differ. 15, 1847-1856.

Hanna, J., Markoulaki, S., Schorderet, P., Carey, B.W., Beard, C., Wernig, M., Creyghton, M.P., Steine, E.J., Cassady, J.P., Foreman, R., Lengner, C.J., Dausman, J.A., Jaenisch, R., 2008. Direct reprogramming of terminally differentiated mature B lymphocytes to pluripotency. Cell 133, 250-264.

Kim, J.B., Zaehres, H., Wu, G., Gentile, L., Ko, K., Sebastiano, V., Arauzo-Bravo, M.J., Ruau, D., Han, D.W. Zenke, M., Scholer, H.R., 2008. Pluripotent stem cells induced from adult neural stem cells by reprogramming with two factors. Nature 454, 646-650.

Kim, J.B., Sebastiano, V., Wu, G., Arauzo-Bravo, M.J., Sasse, P., Gentile, L., Ko, K., Ruau, D., Ehrich, M., van den Boom, D., Meyer, J., Hubner, K., Bernemann, C., Ortmeier, C., Zenke, M., Fleischmann, B.K., Zaehres, H., Scholer, H.R., 2009. Oct4-induced pluripotency in adult neural stem cells. Cell 136, 411-419.

Koch, P., Opitz, T., Steinbeck, J.A., Ladewig, J., Brustle, O., 2009. A rosette-type, selfrenewing human ES cell-derived neural stem cell with potential for in vitro instruction and synaptic integration. Proc. Natl. Acad. Sci. U. S. A. 106, 3225-3230.

Moretti, A., Bellin, M., Jung, C.B., Thies, T.M., Takashima, T., Bernshausen, A., Schiemann, M., Fischer, S., Moosmang, S., Smith, A.G., Lam, J.T., Laugwitz, K.L., 2009. Mouse and human induced pluripotent stem cells as a source for multipotent Isl1 ${ }^{+}$ cardiovascular progenitors. FASEB J.

Nakagawa, M., Koyanagi, M., Tanabe, K., Takahashi, K., Ichisaka, T., Aoi, T., Okita, K., Mochiduki, Y., Takizawa, N., Yamanaka, S., 2008. Generation of induced pluripotent stem cells without Myc from mouse and human fibroblasts. Nat. Biotechnol. 26, 101-106.

Nishimura, K., Nakagawa, T., Ono, K., Ogita, H., Sakamoto, T., Yamamoto, N., Okita, K., Yamanaka, S., Ito, J., 2009. Transplantation of mouse induced pluripotent stem cells into the cochlea. NeuroReport 20 (14), 1250-1254.

Okita, K., Ichisaka, T., Yamanaka, S., 2007. Generation of germline-competent induced pluripotent stem cells. Nature 448, 313-317.

Park, I.H., Arora, N., Huo, H., Maherali, N., Ahfeldt, T., Shimamura, A., Lensch, M.W., Cowan, C., Hochedlinger, K., Daley, G.Q., 2008. Disease-specific induced pluripotent stem cells. Cell 134, 877-886.

Pollard, S.M., Conti, L., Sun, Y., Goffredo, D., Smith, A., 2006. Adherent neural stem (NS) cells from fetal and adult forebrain. Cereb. Cortex 16 (Suppl. 1), i112-i120.

Silva, J., Barrandon, O., Nichols, J., Kawaguchi, J., Theunissen, T.W., Smith, A., 2008. Promotion of reprogramming to ground state pluripotency by signal inhibition. PLoS Biol. e253, 6.

Spiliotopoulos, D., Goffredo, D., Conti, L., Di Febo, F., Biella, G., Toselli, M., Cattaneo, E., 2009. An optimized experimental strategy for efficient conversion of embryonic stem (ES)-derived mouse neural stem (NS) cells into a nearly homogeneous mature neuronal population. Neurobiol. Dis. 34, 320-331.

Stadtfeld, M., Brennand, K., Hochedlinger, K., 2008. Reprogramming of pancreatic beta cells into induced pluripotent stem cells. Curr. Biol. 18, 890-894.

Sun, Y., Pollard, S., Conti, L., Toselli, M., Biella, G., Parkin, G., Willatt, L., Falk, A., Cattaneo, E., Smith, A., 2008. Long-term tripotent differentiation capacity of human neural stem (NS) cells in adherent culture. Mol. Cell. Neurosci. 38, 245-258.

Takahashi, K., Yamanaka, S., 2006. Induction of pluripotent stem cells from mouse embryonic and adult fibroblast cultures by defined factors. Cell 126, 663-676.

Takahashi, K., Tanabe, K., Ohnuki, M., Narita, M., Ichisaka, T., Tomoda, K., Yamanaka, S., 2007. Induction of pluripotent stem cells from adult human fibroblasts by defined factors. Cell 131, 861-872.

Wernig, M., Zhao, J.P., Pruszak, J., Hedlund, E., Fu, D., Soldner, F., Broccoli, V., Constantine-Paton, M., Isacson, O., Jaenisch, R., 2008. Neurons derived from reprogrammed fibroblasts functionally integrate into the fetal brain and improve symptoms of rats with Parkinson's disease. Proc. Natl. Acad. Sci. U. S. A. 105, 5856-5861.

Xu, H., Wang, W., Li, C., Yu, H., Yang, A., Wang, B., Jin, Y., 2009. WWP2 promotes degradation of transcription factor OCT4 in human embryonic stem cells. Cell Res. 19, 561-573.

Xu, H.M., Liao, B., Zhang, Q.J., Wang, B.B., Li, H., Zhong, X.M., Sheng, H.Z., Zhao, Y.X., Zhao, Y.M., Jin, Y., 2004. Wwp2, an E3 ubiquitin ligase that targets transcription factor Oct-4 for ubiquitination. J. Biol. Chem. 279, 23495-23503.

Yamanaka, S., 2009. A fresh look at iPS cells. Cell 137, 13-17.

Ying, O.L., Stavridis, M., Griffiths, D., Li, M., Smith, A., 2003. Conversion of embryonic stem cells into neuroectodermal precursors in adherent monoculture. Nat. Biotechnol. 21, 183-186.

Yu, J., Vodyanik, M.A., Smuga-Otto, K., Antosiewicz-Bourget, J., Frane, J.L., Tian, S., Nie, J., Jonsdottir, G.A., Ruotti, V., Stewart, R., Slukvin, II, Thomson, J.A., 2007. Induced pluripotent stem cell lines derived from human somatic cells. Science 318, 1917-1920. 